\title{
Immune Activation in the Liver by Nucleic Acids
}

\author{
Qian Sun, Qingde Wang, Melanie J. Scott and Timothy R. Billiar* \\ Department of Surgery, University of Pittsburgh, Pittsburgh, PA, USA
}

\begin{abstract}
Viral infection in the liver, including hepatitis B virus (HBV) and hepatitis $C$ virus (HCV) infection, is a major health problem worldwide, especially in developing countries. The infection triggers a pro-inflammatory response in patients that is crucial for host defense. Recent studies have identified multiple transmembrane and cytosolic receptors that recognize pathogen-derived nucleic acids, and these receptors are essential for driving immune activation in the liver. In addition to sensing DNA/RNA from pathogens, these intracellular receptors can be activated by nucleic acids of host origin in response to sterile injuries. In this review, we discuss the expanding roles of these receptors in both immune and nonimmune cells in the liver.
\end{abstract}

(C) 2016 The Second Affiliated Hospital of Chongqing Medical University. Published by XIA \& HE Publishing Inc. All rights reserved.

\section{Introduction}

The activation of innate immune pathways is crucial for host defense in response to invasive pathogens and during sterile inflammation, as observed after tissue trauma or ischemia. In the setting of microbial infection, pathogen-associated molecular patterns (PAMPs), which are conserved microbial motifs, can be recognized by pattern recognition receptors

Keywords: Nucleic acid; Innate immunity; Intracellular receptor; Hepatocytes. Abbreviations: ADAR1, adenosine deaminase acting on RNA1; AIM2, absent in melanoma 2; ASC, apoptosis-associated speck-like protein containing a caspase recruitment domain; CARD, caspase activation and recruitment domain; cGAS cyclic GMP-AMP synthase; CMV, cytomegalovirus; CpG, cytosine-phosphateguanine; DAI, DNA-dependent activator of IRF; DAMP, damage-associated molecular pattern; dsRNA, double-stranded RNA; HMGB1, high-mobility group box 1 ; IFI16, gamma-interferon-inducible protein 16; IFN, interferon; IL, interleukin; $I / R$, ischemia/reperfusion; iNOS, inducible nitric oxide synthase; IRF, interferon regulatory factor; ISGs, interferon-stimulated genes; LGP2, laboratory of genetics and physiology 2; LRR, leucine-rich repeat; MDP, muramyldipeptide; MDA5, melanoma differentiation-associated protein 5; mtDNA, mitochondrial DNA; MyD88, myeloid differentiation primary-response protein $88 ; \mathrm{NF}-\kappa \mathrm{B}$, nuclear factor $\kappa \mathrm{B}$; NLRs, NOD-like receptors; NOD2, nucleotide-binding oligomerization domain protein 2; PAMP, pathogen-associated molecular patterns; pgRNA, pregenomic RNA; PKR, protein kinase R; Pol-III, polymerase III; poly[I:C], polyinosinicpolycytidylic acid; PRRs, pattern recognition receptors; RANTES, regulated upon activation, normal T cell expressed and secreted; RIG-I, retinoic acid-inducible gene I; RLRs, RIG-I like receptors; ROS, reactive oxygen species; sSRNA, singlestranded RNA; STAT1/2, signal transducer and activator of transcription $1 / 2$; STING, stimulator of IFN genes; TLRs, Toll-like receptors; TNF $\alpha$, tumor necrosis factor alpha; TRAF6, tumor necrosis factor receptor-associated factor 6; TRIF, TIR domain-containing adaptor inducing IFN- $\beta$; UTRs, untranslated regions.

Received: 15 January 2016; Revised: 24 February 2016; Accepted: 7 March 2016 DOI: $10.14218 / \mathrm{JCTH} .2016 .00003$.

*Correspondence to: Timothy R. Billiar, Department of Surgery, University of Pittsburgh, Suite F1281, 200 Lothrop Street, Pittsburgh, PA 15213, USA. Tel: +1-412-647-1749, Fax: +1-412-647-3247, Email: billiartr@upmc.edu
(PRRs) expressed by both immune and nonimmune cells. ${ }^{1,2}$ This pathway leads to the eradication of pathogens through numerous clearance mechanisms that involve the production of inflammatory mediators, cell recruitment, and activation. Similarly, the same PRRs can be activated in response to sterile injuries by endogenous activators known as damageassociated molecular patterns (DAMPs). For example, nucleic acids of microbial or host origin represent a major category of both PAMP and DAMP. These "non-self" or "self-originated" molecules are detected by PRRs, including toll-like receptors (TLRs), nucleotide-oligomerization domain (NOD)-like receptors (NLRs), and retinoic acid-inducible gene (RIG)-I like receptors (RLRs), which initiate cell signaling and gene expression.

The liver, by virtue of its anatomical position "downstream" from the gastrointestinal tract and as the target of many heterotrophic viruses, is adapted to recognize invading pathogens as well as toxic insults that lead to liver injury. These innate immune recognition pathways are present in essentially all of the resident cells in the liver, which include not only resident cells of the immune system such as Kupffer cells but also the parenchymal cells or hepatocytes. The liver integrates its important and unique roles in metabolism with its functions in local and systemic immune responses. If damaged, the liver can co-opt these metabolic and immune responses to regenerate its mass. All of these responses involve the robust synthesis and turnover of nucleic acids that must be compartmentalized or sequestered to regulate appropriate nucleic acid sensing. Here, we review recent advances in our understanding of nucleic acid sensing by PRRs in liver cells.

\section{Intracellular nucleic acid sensors in the liver}

Innate immune sensors involved in the recognition of nucleic acids can be divided into two groups based on their subcellular localization. TLRs, including TLR3, TLR7, TLR8, and TLR9, are membrane-bound receptors that monitor endolysosomes for pathogen or host derived nucleic acids. ${ }^{3,4}$ A second group of receptors recognize nucleic acids in the cytoplasm and is further classified here into those that recognize cytosolic DNA and those that detect pathogen- or hostderived RNA.

\section{Nucleic acid sensing by TLRs}

TLRs are transmembrane receptors composed of ligand binding ectodomain and transmembrane domains as well as a cytosolic domain that is crucial for the recruitment of downstream adaptors, including myeloid differentiation primaryresponse protein 88 (MyD88) and TIR domain-containing 
adaptor inducing interferon (IFN)- $\beta$ (TRIF). ${ }^{5}$ Each TLR family member recognizes specific nucleic acid ligands, partly through a leucine-rich repeat (LRR) motif in the luminal ectodomain. ${ }^{4}$ Among the TLRs involved in nucleic acid sensing, TLR3 recognizes double-stranded RNA (dsRNA), including a synthetic dsRNA analog polyinosinic-polycytidylic acid (poly $[\mathrm{I}: \mathrm{C}]$ ), as well as single-stranded RNA (ssRNA) derived from encephalomyocarditis virus and West Nile virus. ${ }^{4,6}$ TLR7 and TLR8, on the other hand, were only shown to be activated by ssRNA, especially GU-rich ssRNA. ${ }^{7}$ TLR9 is a sensor for unmethylated cytosine-phosphate-guanine (CpG) DNA motifs that are enriched in bacterial and mitochondrial genomes. ${ }^{8}$

Upon recognition of nucleic acids by TLRs, two signaling pathways can be activated: recruitment of the adaptor protein TRIF by TLR3 and recruitment of MyD88 by TLR7, TLR8, and TLR9. ${ }^{9}$ Whereas both of the adaptor proteins trigger nuclear factor kappa B (NF-kB) mediated upregulation of proinflammatory cytokines, such as interleukin (IL)- 6 and tumor necrosis factor alpha $(\mathrm{TNF} \alpha)$, transcription factor interferon regulatory factor 3 (IRF3) is only activated by TRIF, and IRF7 is only activated by MyD88. ${ }^{10}$ Activation of both IRF3 and IRF7 subsequently induce production of type I IFN in immune and nonimmune cells, ${ }^{9,11}$ which in particular is essential for immune responses to viral pathogens.

\section{Cytosolic RNA sensors}

RLRs are a group of well-characterized cytosolic RNA sensors responsible for intracellular dsRNA-induced type-I IFN production. ${ }^{12}$ All three members of the RLR family, RIG-I, melanoma differentiation-associated protein 5 (MDA5), and laboratory of genetics and physiology 2 (LGP2), are broadly expressed by both immune and nonimmune cells such as hepatocytes, making them essential in the host response against viral infection in the liver. ${ }^{9,13}$

Both RIG-I and MDA5 recognize dsRNA, including the synthetic analog poly (I:C). However, they have been shown to respond preferentially to RNA ligands of variable lengths. MDA5 generally recognizes long dsRNA molecules ( $>2 \mathrm{~kb}$ ), whereas RIG-I preferentially binds to shorter fragments of dsRNA with an uncapped $5^{\prime}$ triphosphate end. ${ }^{9,12}$ A few studies have shown that RIG-I may also be involved in host immune response to cytosolic viral and bacterial dsDNA, but it was suggested that RNA polymerase III (Pol-III) was required for this process as Pol-III converts pathogen dsDNA to dsRNA. $3,9,14$ Very little is known about the RNA ligands that can activate LGP2, but recent studies suggest that its ATPase activity may regulate RIG-I- and MDA5-dependent type I IFN production in response to viral infection. ${ }^{12,15}$

Upon recognition of cytosolic dsRNA by RIG-I and MDA5, the $\mathrm{N}$-terminal caspase activation and recruitment domains (CARDs) associate with the adaptor protein mitochondrial antiviral signaling (MAVS, also known as IPS1), and the interaction subsequently leads to the activation of transcription factors IRF3, IRF7, and NF-кB. ${ }^{12}$ As discussed above, activation of these transcription factors results in the production of IFNs and pro-inflammatory cytokines, which are important in host defense against viruses. The transmembrane protein stimulator of IFN genes (STING) was also shown to be important for RIG-I-dependent IFN production, although the details of the mechanism remain unclear. $^{9}$

In addition to RLRs, a few other cytosolic RNA sensors have recently been described. Protein kinase $R$ (PKR) is a serine/ threonine kinase that can be activated by dsRNA. ${ }^{12}$ Upon activation, it was shown to induce a type I IFN response by stabilizing IFN- $\alpha /$ IFN- $\beta$ transcripts downstream of MDA5 signaling. ${ }^{16,17}$ PKR has been found to contain a dsRNA-binding domain, but it remains unknown as to whether it could function independently of RLRs or TLR3 to produce IFN. ${ }^{4,18}$ Interestingly, PKR is also involved in the activation of the inflammasome in response to dsRNA and the release of nuclear protein high-mobility group box 1 (HMGB1), which triggers the production of more cytokines from the activated macrophages. ${ }^{19}$ A recent study showed that nucleotidebinding oligomerization domain protein 2 (NOD2) can serve as a cytosolic ssRNA sensor and trigger type I IFN production in response to viral infection. ${ }^{20}$

In general, this category of RNA sensors detects viral RNA and their replicons in the cytoplasm, differentiating them from cell membrane bound or endosome located TLRs that detect PAMPs from the extracellular space. As abundant autogenic RNA exist in the cytoplasm under physiological conditions, these receptors are likely capable of distinguishing between "self" and "non-self" molecules. Importantly, however, under certain pathologic conditions, such as liver ischemia/reperfusion injury, they can react to autogenic RNAs that are released to the extracellular space or in the cytosol to elicit inflammatory reactions.

\section{Cytosolic DNA sensors}

Compared to cytosolic RNA sensors, receptors for cytosolic DNA are controversial and elusive. Two major signaling pathways have been described for cytosolic DNA-sensing: one is mediated by the adaptor protein STING to induce IFN production, and the other is mediated by activation of the inflammasome to trigger production of IL-1 $\beta$ and IL-18. DNA-dependent activator of IRF (DAI, also known as ZBP1), gamma-interferon-inducible protein 16 (IFI16), and the RNA helicase DDX41 have all been reported to recognize dsDNA in the cytosol and trigger type I IFN production through the STING/TBK1/IRF3 pathway. ${ }^{4,9}$ In addition, a recently discovered cytosolic receptor cyclic GMP-AMP synthase (cGAS) was shown to detect cyclic dinucleotides derived from bacterial cells and to induce type I IFN in a STING-dependent manner. 4,21

Most of the intracellular nucleic acid-sensing pathways discussed thus far lead to the production of IFNs vital to combat viral infection. However, there is yet another group of nucleic acid-sensing receptors that have been shown to cause the maturation of pro-inflammatory cytokines IL-1 $\beta$ and IL-18, cytokines important in host response to bacterial infection as well as sterile inflammation. A typical inflammasome contains a NLR or an absent in melanoma 2 (AIM2), apoptosis-associated speck-like protein containing a caspaserecruitment domain (ASC), and procaspase-1. Inflammasome activation leads to autocleavage of caspase-1, forming the active caspase- 1 p10/p20 tetramer that cleaves pro-IL-1 $\beta$ and pro-IL-18 into their active forms. ${ }^{22}$ In addition, inflammasomes play unique roles in hepatocytes, which do not produce IL- $1 \beta$ or IL-18. Others have shown that caspase- 1 activation regulates enzymes involved in glycolysis, ${ }^{23}$ while we have shown that inflammasome activation upregulates mitochondrial autophagy in hypoxic hepatocytes. ${ }^{24}$ Recent research has identified AIM2 as the receptor for cytosolic dsDNA derived from bacteria and viruses. ${ }^{25}$ However, little is known about the ligand specificity of AIM2, and it appears that AIM2 can be activated by dsDNA from various sources, whether 
from bacteria, virus, or host. ${ }^{4,26}$ It was also recently shown that cytosolic mitochondrial DNA (mtDNA) and more specifically, oxidized mtDNA, contributes to the secretion of IL-1 $\beta$ and IL- 18 by activating the NLRP3 inflammasome. ${ }^{27}$ However, whether NLRP3 can directly sense mtDNA that is released into the cytosol is still unclear.

\section{Recognition of HBV by intracellular nucleic acid} sensors in the liver

Human HBV is a small DNA virus that causes hepatic inflammation and is associated with substantial morbidity worldwide. ${ }^{28}$ Around 400 million people worldwide are chronically infected with HBV, substantially increasing their risk of developing cirrhosis and hepatocellular carcinoma. ${ }^{28}$ Although the underlying mechanisms leading to host defense against HBV infection remain to be clearly defined, there is emerging evidence that innate immunity and especially IFN response are essential for clearance of intrahepatic HBV. ${ }^{13,29,30}$ Moreover, IFN and nucleoside analogs are currently available for HBV treatment, suggesting the important role of host innate immune response in viral elimination. ${ }^{30,31}$

The HBV genome comprises a relaxed partially dsDNA of approximately $3.2 \mathrm{~kb} \cdot{ }^{30,32}$ Upon entry and uncoating of HBV in hepatocytes, the relaxed circular DNA ( $r C D N A)$ is converted into covalently closed circular DNA, which is then transcribed to generate four RNA species: the $0.7 \mathrm{~kb}, 2.1 \mathrm{~kb}, 2.4 \mathrm{~kb}$, and $3.5 \mathrm{~kb}$ viral RNA transcripts. ${ }^{32}$ The RNA species are exported to the cytoplasm and then translated into HBV proteins. The longest $3.5 \mathrm{~kb}$ viral RNA is also known as the pregenomic RNA (pgRNA) that serves as the template for reverse transcription and synthesis of new rcDNA.

Given the life cycle of HBV, both DNA and RNA can potentially serve as PAMPs to activate cytosolic nucleic acid sensors. Indeed, two recent studies have identified the roles of two RNA sensors, RIG-I and MDA5, in the recognition of $\mathrm{HBV}$ virus and host defense response (table 1). ${ }^{30,32}$ In the first study, the authors showed that the RNA sensor RIG-I was essential for the recognition of HBV genotypes $A, B$, and $C$ and for induction of type III IFN expression in human hepatocytes. ${ }^{30}$ Moreover, their study suggests that the $5^{\prime}-\varepsilon$ region of HBV pgRNA interacts with RIG-I and is a key element for RIG-I dependent IFN- $\lambda 1$ induction. However, for genotype D HBV, the second study showed that MDA5, but not RIG-I, is critical for the expression of IFN-stimulated genes (ISGs) following infection. ${ }^{32}$ The discrepancy between the two studies could be due to distinct genomic sequence of HBV genotype D. ${ }^{33}$ Interestingly, AIM2-dependent inflammasome formation and the production of IL-1 $\beta / \mathrm{IL}-18$ have been found during HBV infection. ${ }^{34}$

\section{Recognition of HCV by intracellular nucleic acid sensors in the liver}

HCV infects nearly 200 million people worldwide, and $80 \%$ of infected individuals develop chronic inflammation that may eventually progress to cirrhosis or liver cancer. ${ }^{35,36}$ The HCV genome contains a positive-sense RNA comprised of highly structured $5^{\prime}$ and $3^{\prime}$ untranslated regions (UTRs) and a large open reading frame that encodes HCV structural and nonstructural proteins. ${ }^{37}$ Similar to the treatment of HBV, $\mathrm{HCV}$ infection is treated with an IFN- $\alpha$-based therapy, ${ }^{38}$ suggesting the important role of innate immune response in host defense against HCV.
A few RLRs have been identified that sense cytosolic HCV RNA. RIG-I binds to HCV RNA and signals IRF3 activation to induce the expression of IFNs and ISGs that are essential for viral elimination. ${ }^{37,39-41}$ RIG-I signaling has been proposed to be negatively regulated by formation of a multimeric complex that is controlled by the internal repressor domain at the $\mathrm{C}$ terminus of RIG-I. ${ }^{42}$ Another RLR LGP2 was shown to bind to HCV RNA, but it functions as a negative regulator of host defense mediated by RIG-I. ${ }^{42}$ Interestingly, a recent study suggested that MDA5 also plays a critical role in IFN response during HCV infection, and the function of RIG-I maybe limited only to early sensing of the virus infection. ${ }^{35}$

HCV RNA replication was also shown to trigger dsRNAinduced antiviral pathways mediated by PKR in human hepatoma cells. ${ }^{43}$ Interestingly, the viral nonstructural 5A protein was found to bind PKR and block the PKR-dependent IFN response, suggesting the potential role of PKR as a cytosolic HCV RNA sensor. NALP3, a NLR that triggers activation of the inflammasome, has also been indicated to sense $\mathrm{HCV}$ and induce the secretion of IL-1 $\beta$ through assembly of the inflammasome complex. ${ }^{44,45}$ However, no studies have demonstrated that NLRP3 directly binds nucleic acids (DNA or RNA), and thus it is possible that NLRP3 in this case is activated by increased reactive oxygen species (ROS) production instead. ${ }^{45}$ Another study by Li et al. suggests that TLR3 senses HCV dsRNA that is longer than 80-100 base pairs, resulting in $\mathrm{NF}-\kappa \mathrm{B}$ activation and the production of regulated upon activation, normal T cell expressed and secreted (RANTES), macrophage inflammatory protein-1 alpha (MIP-1 $\alpha$ ), MIP-1 $\beta$, IP-10, and IL-6 in hepatocytes. ${ }^{46}$

Recognition of adenovirus and cytomegalovirus (CMV) by intracellular nucleic acid sensors in the liver

Adenovirus and CMV are dsDNA viruses that typically target tissues other than the liver. ${ }^{47}$ However, in immunocompromised and liver transplant patients, adenovirus and CMV infections are associated with the development of hepatitis and possibly fulminant liver failure. ${ }^{47,48} \mathrm{CMV}$, for example, accounts for symptomatic infection in $40 \%$ of pediatric liver transplant recipients, and it is associated with substantial morbidity and mortality in these patients. ${ }^{49}$

An IRF3-dependent type I IFN response was reported in macrophages in response to adenovirus infection. ${ }^{14,50,51}$ A variety of DNA sensors, including DDX41, Pol-III, and cGAS, have been identified to sense cytosolic dsDNA derived from adenovirus. ${ }^{14,50,51}$ Infection of a macrophage-like cell line was shown to trigger upregulation of IRF3 primary response genes, such as ISG56 and IFN- $\beta$, within 2- 6 hours and to induce later the phosphorylation of signal transducer and activator of transcription 1/2 (STAT1/2), a type I IFN secondary signaling molecule, to amplify further the antiviral response. ${ }^{50,51}$ Interestingly, as an enzyme responsible for transcribing DNA template into RNA, Pol-III was reported to sense adenoviral dsDNA in the cytosol and trigger RIG-Idependent IFN production. ${ }^{14}$

Mouse CMV infection was shown to activate two nucleic acid receptors on the endosomal membrane, TLR9 and TLR3, and trigger two nonredundant pathways mediated by MyD88 and TRIF, respectively. ${ }^{52}$ Both of the receptors are required for type I IFN production in response to mouse CMV infection, whereas neither pathway is enough to provide full protection against the virus. ${ }^{52}$ Two cytosolic DNA sensors, DAI and IFI16, were also shown to be important for the induction of 
Sun Q. et al: Nucleic acid sensing by immune system

Table 1. Nucleic acid sensing by pattern recognition receptors (PRRs) in liver infection and diseases

\begin{tabular}{|c|c|c|c|c|c|c|}
\hline Virus & PRR & $\begin{array}{l}\text { Nucleic } \\
\text { Acid }\end{array}$ & $\begin{array}{l}\text { Experimental } \\
\text { System }\end{array}$ & $\begin{array}{l}\text { Signaling } \\
\text { Pathway }\end{array}$ & $\begin{array}{l}\text { Cytokine } \\
\text { production }\end{array}$ & References \\
\hline \multirow[t]{3}{*}{ Adenovirus } & DDX41 & dsDNA & Macrophage & $\begin{array}{l}\text { TBK1/STING- } \\
\text { IRF3 }\end{array}$ & $\operatorname{IFN} \beta$ & 51 \\
\hline & Pol-III/RIG-I & dsDNA & Macrophage & RIG-I-IRF3 & $\operatorname{IFN} \beta$ & 14 \\
\hline & cGAS & dsDNA & Macrophage & STING-IRF3 & IFN $\beta$ & 50 \\
\hline \multirow[t]{4}{*}{ CMV } & IFI16 & dsDNA & Macrophage & STING-IRF3 & IFN $\beta$ & 54 \\
\hline & DAI & dsDNA & Fibroblast & IRF3 & IFN $\beta$ & 53 \\
\hline & AIM2 & dsDNA & In vivo & Inflammasome & IL-1 $\beta / I L-18$ & 25 \\
\hline & TLR9/TLR3 & dsDNA & In vivo & MyD88/TRIF & $\operatorname{IFN} \alpha / \beta / \gamma$ & 52 \\
\hline \multirow[t]{3}{*}{ HBV } & AIM2 & dsDNA & $\begin{array}{l}\text { Glomerular } \\
\text { mesangial cell }\end{array}$ & Inflammasome & IL- $1 \beta / I L-18$ & 34 \\
\hline & MDA5 & RNA & Hepatocyte & IRF3 & IFN $\beta$ & 32 \\
\hline & RIG-I & pgRNA & Hepatocyte & IRF3/NFKB & $\operatorname{IFN} \lambda$ & 30 \\
\hline \multirow[t]{5}{*}{$\mathrm{HCV}$} & NLRP3 & RNA & $\begin{array}{l}\text { Hepatocyte/ } \\
\text { Macrophage }\end{array}$ & Inflammasome & IL-1 $\beta$ & 44,45 \\
\hline & TLR3 & DsRNA & Hepatocyte & NF-кB & $\begin{array}{l}\text { RANTES, MIP- } 1 \alpha \text {, } \\
\text { MIP- } 1 \beta, \text { IP- } 10 \\
\text { and IL-6 }\end{array}$ & 46 \\
\hline & PKR & RNA & Hepatocyte & IRF1 & - & 43 \\
\hline & RIG-I & RNA & Hepatocyte & IRF3 & IFN $\alpha / \beta /$ ISG & $37,39,42$ \\
\hline & MDA5 & dsRNA & Hepatocyte & IRF3 & $\operatorname{IFN} \beta / \lambda$ & 35 \\
\hline \multirow[t]{2}{*}{ mtDNA } & NLRP3 & $\begin{array}{l}\text { Oxidized } \\
\text { dsDNA }\end{array}$ & Macrophage & Inflammasome & IL-1 $\beta$ & 27 \\
\hline & TLR9 & dsDNA & In vivo & MyD88 & IL-1 $\beta /$ IL-6/IFN $\alpha$ & 8,67 \\
\hline $\begin{array}{l}\text { Apoptotic or } \\
\text { necrotic DNA }\end{array}$ & TLR9 & dsDNA & In vivo & MyD88 & IL-1 $\beta / \mathrm{IL}-18 / \mathrm{IL}-6 / \mathrm{TNF} \alpha$ & 56,57 \\
\hline Histone/DNA & TLR9 & - & Kupffer cells & MyD88 & IL-1 $/$ IL-18/IL-6/TNF $\alpha$ & 59,68 \\
\hline Plasmodium & MDA5 & RNA & Hepatocyte & IRF3/IRF7 & IFN $\alpha / \beta /$ ISG & 66 \\
\hline
\end{tabular}

Abbreviations: AIM2, absent in melanoma 2; cGAS, cyclic GMP-AMP synthase; CMV, cytomegalovirus; DAI, DNA-dependent activator of IRF; dsRNA, double-stranded RNA; HBV, hepatitis B virus; HCV, hepatitis C virus; IFI16, gamma-interferon-inducible protein 16; IFN, interferon; IL, interleukin; IRF, interferon regulatory factor; ISG, interferon-stimulated gene; MDA5, melanoma differentiation-associated protein 5; mtDNA, mitochondrial DNA; MyD88, myeloid differentiation primary-response protein 88; pgRNA, pregenomic RNA; PKR, protein kinase R; Pol-III, polymerase III; PRRs, pattern recognition receptors; RANTES, regulated upon activation, normal T cell expressed and secreted; RIG-I, retinoic acid-inducible gene I; STING, stimulator of IFN genes; TLRs, Toll-like receptors; TNF $\alpha$, tumor necrosis factor alpha; TRIF, TIR domain-containing adaptor inducing IFN- $\beta$.

IFN- $\beta$ following human CMV infection in macrophages. ${ }^{53,54}$ In addition, AIM2 was suggested to sense dsDNA derived from mouse CMV and induce the release of IL-1 $\beta$ and IL-18 in vivo. ${ }^{25} \mathrm{IL}-18$, in turn, was shown to induce further IFN- $\gamma$ production by natural killer cells in the spleens of CMV-infected mice and results in enhanced control of virus replication. ${ }^{25}$

\section{Recognition of host nucleic acids in the liver}

Cytosolic nucleic acids derived from the host itself represent a group of DAMPs that cause sterile inflammation in the context of cell stress and tissue damage. DNA derived from mitochondria is of particular interest given its similarities to bacterial DNA, which contains immune activating unmethylated CpG motifs. ${ }^{8,55}$ Mitochondria damaged by cellular stress are degraded by autophagy in immune cells as well as nonimmune cells, including hepatocytes. 8,24 It was reported that mitochondrial DNA that escapes from autophagy causes IL-1 $\beta$ and IL- 6 production through activation of TLR9 on the lysosomal membrane. ${ }^{8}$ Cytosolic oxidized mtDNA, on the other hand, has been shown to induce IL-1 $\beta$ secretion upon binding to NLRP3. ${ }^{27}$ However, although mtDNA can be pulled down with NLRP3 by immunoprecipitation, whether NLRP3 directly interacts with mtDNA remains to be determined.

In models that induce sterile injury in the liver, such as liver ischemia/reperfusion (I/R) and acetaminophen overdose, DNA released from host cells serves as a major source of DAMP to trigger inflammation and liver injury. In an acetaminophen-induced hepatotoxicity model, for example, activation of TLR9 by DNA released from apoptotic and necrotic hepatocytes was shown to trigger the upregulation of pro-IL-1 $\beta$, pro-IL-18, and TNF $\alpha_{.}{ }^{56,57}$ Interestingly, in the model of liver I/R, disruption of TLR9 activation by injecting inhibitory CPG immediately before I/R was shown to reduce significantly the release of proinflammatory cytokines IL-6 and TNF by immune cells. ${ }^{58}$ Moreover, it has been shown that circulating levels of histones, proteins associated with DNA in the nucleus, are significantly increased after liver I/R. These extracellular histones are able to enhance DNAmediated TLR9 activation during this process. ${ }^{59}$ Our own 


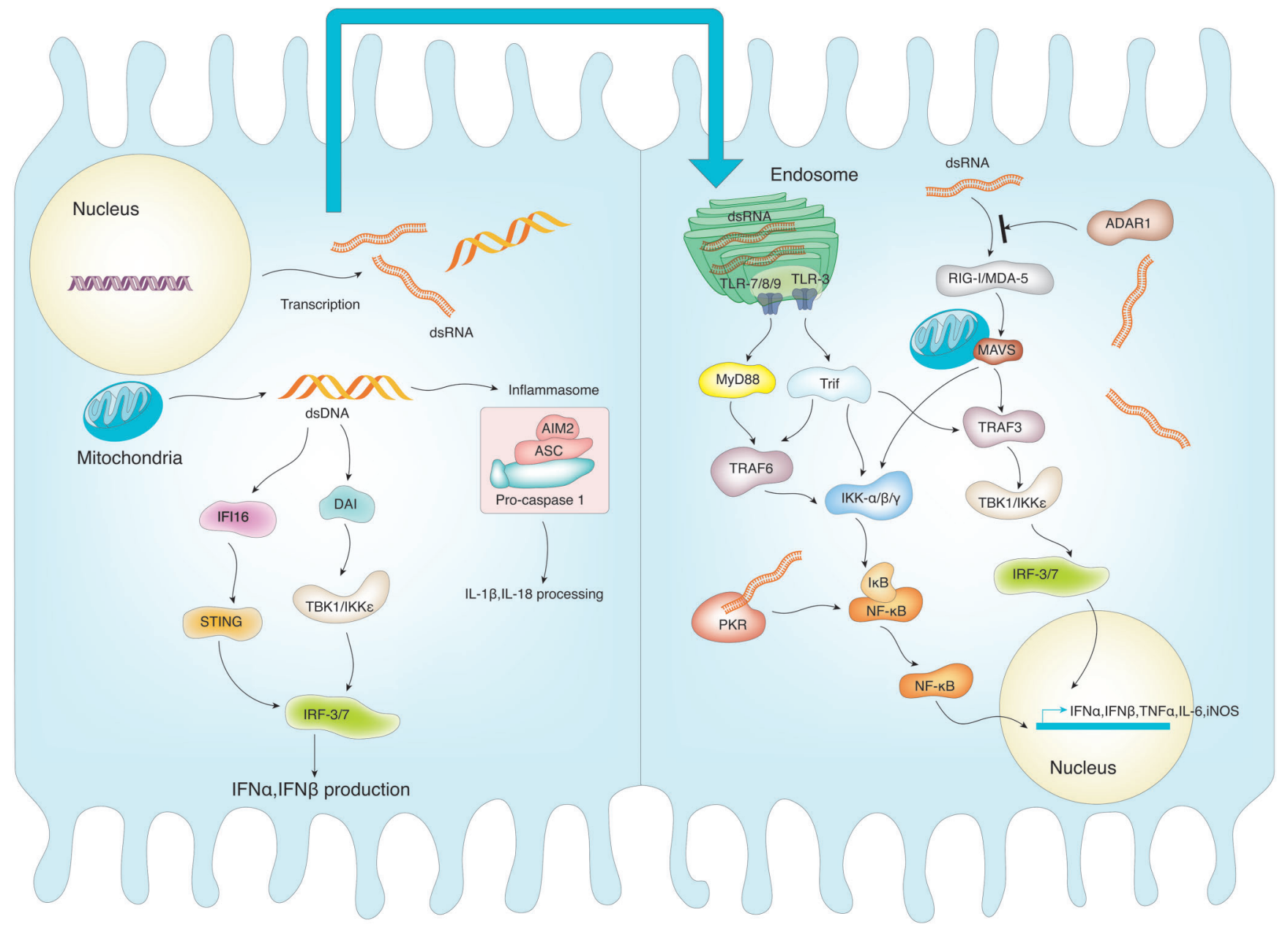

Fig. 1. Nucleic acid sensing pathways via intracellular DNA/RNA receptors. Under normal biological conditions, hepatocytes exhibit abundant nucleic acid synthesis. Under pathological conditions, mitochondria DNA and cellular RNA transcripts serve as damage-associated molecular patterns (DAMPs) to trigger inflammatory response by activating cytosolic receptors and downstream signaling pathways. In addition, RNA/DNA can be released to the extracellular space, leading to activation of endosomal receptors, such as toll-like receptor (TLR)3, TLR7, and TLR9. While stimulation of TLRs lead to inflammatory cytokine production, primarily via myeloid differentiation primary-response protein 88 (MyD88), tumor necrosis factor receptor-associated factor 6 (TRAF6), nuclear factor kappa B (NF-kB), and mitogen activated protein kinase (MAPK) pathways, dsRNA predominantly causes activation of interferon (IFN) pathways by phosphorylation of interferon regulatory factors (IRFs).

data also suggest that AIM2, an inflammasome protein that triggers activation of caspase- 1 , is essential for sensing cytosolic dsDNA in hepatocytes after redox stress induced by hemorrhagic shock with resuscitation (manuscript submitted), which represents another mechanism of the recognition of nucleic acids derived from host itself (Fig. 1). Rather than leading to cytokine release, activation of AIM2 and caspase-1 in hepatocytes is responsible for upregulation of cellular adaptive responses, such as mitochondrial autophagy and subsequent hepatoprotection in response to redox stress.

Cellular RNA is a potent and important signal of danger that activates innate immune response in hepatocytes under pathologic conditions. We have provided evidence that adenosine deaminase acting on RNA1 (ADAR1), an RNA editing enzyme, is important to prevent detection of cytosolic self RNA in hepatocytes (Fig. 1). ${ }^{60,61}$ We showed in a cell model that suppression of ADAR1 expression leads to enhanced RIG-I activation and IFN production following I/R that results in increased organ damage. ${ }^{62}$ Deletion of ADAR1 gene in mice also leads to type I IFN production and tissue damage in liver under sterile conditions. Moreover, a recent study by Pestal et al. showed that ADAR1 negatively regulates the RLR-MAVS-IFN pathway and plays an essential role in organ development. ${ }^{63}$ We have found that hepatocytes utilize TLR3 and PKR to detect the dsRNA mimic Poly (I:C) leading to IRF3 and 7 upregulation and type 1 IFN production (manuscript submitted). Taken together, the recent observations on the role of self-sensing nucleic acids in the liver could explain, in part, the pathways leading to type I IFN-induced liver damage in I/R. ${ }^{64}$ The role of self-derived nucleic acids in driving both immune responses and hepatic immunopathology is a fertile area for further investigation.

\section{Cell-specific nucleic acid sensing in the liver}

Many of the nucleic acid sensing pathways described above lead to an antiviral response that is dependent on cytokine production. Given that hepatocytes are the major targets of liver viruses, such as HBV and HCV, and they do not produce high levels of cytokines, ${ }^{24}$ it is likely that the nucleic acid 
sensors in hepatocytes are playing different roles than those in immune cells. One of those roles is the production of chemokines and IFNs in response to viral infection. ${ }^{46,65}$ Cytosolic RNA sensor MDA5, for example, was shown to sense RNA derived from the Plasmodium parasite and to trigger a type I IFN program in hepatocytes. ${ }^{66}$ Although the liver stage of Plasmodium infection was previously believed to be clinically silent, the authors showed that this type I IFN response in hepatocytes controls liver parasite load and delays the onset of blood parasitemia. ${ }^{11,66}$ The increase in type I IFN signaling, including upregulation of ISGs after Plasmodium infection, was shown to occur independently of all TLRs or RIG-I, but MDA5 and the adaptor protein MAVS were essential to trigger IRF3/IRF7 induced ISG expression in hepatocytes. ${ }^{66}$ Moreover, using hepatocyte-specific IFN $\alpha$ receptor 1 knockout (ifnar1-/-) mice, Liehl et al. found that type I IFN signaling triggered within hepatocytes is required for recruitment of immune cells to the site of infection and subsequent parasite elimination. ${ }^{66}$ Another RNA sensor, NOD2, is also highly expressed in hepatocytes. ${ }^{65}$ It has been shown that although activation of NOD2 does not lead to chemokine production in hepatocytes, it does synergize with dsRNA polyI:C to activate NF-кB in those cells. ${ }^{65}$

\section{Conclusion}

Viral infection in the liver is a major health problem worldwide, especially in developing countries. Multiple transmembrane and cytosolic receptors have recently been identified to recognize viral RNA and DNA, leading lead to the secretion of pro-inflammatory cytokines, including IFNs. Understanding these nucleic acid sensing mechanisms is, therefore, critical for the development of new therapies. It is clear that both immune cells and nonimmune cells can recognize nucleic acid of both microbial and host origin. However, the cell types differ in response to nucleic acid sensing, and the different responses in various cell types remains to be fully elucidated.

\section{Acknowledgements}

Work funded through grant from NIH to TRB (R01GM044100).

\section{Conflict of interest}

None

\section{Author contributions}

Proposed the concept of the review (TRB), wrote the manuscript (QS, QW), and critically reviewed the manuscript (TRB, $\mathrm{MJS})$.

\section{References}

[1] Chen GY, Nuñez G. Sterile inflammation: Sensing and reacting to damage. Nat Rev Immunol 2010;10:826-837. doi: 10.1038/nri2873.

[2] Areschoug T, Gordon S. Pattern recognition receptors and their role in innate immunity: Focus on microbial protein ligands. Contrib Microbiol 2008;15: 45-60. doi: 10.1159/000135685.

[3] Broz P, Monack DM. Newly described pattern recognition receptors team up against intracellular pathogens. Nat Rev Immunol 2013;13:551-565. doi: $10.1038 /$ nri3479.
[4] Barbalat R, Ewald SE, Mouchess ML, Barton GM. Nucleic acid recognition by the innate immune system. Annu Rev Immunol 2011;29:185-214. doi: 10.1146/ annurev-immunol-031210-101340.

[5] Takeda K, Akira S. TIr signaling pathways. Semin Immunol 2004;16:3-9. doi: $10.1016 /$ j.smim.2003.10.003.

[6] Alexopoulou L, Holt AC, Medzhitov R, Flavell RA. Recognition of doublestranded rna and activation of nf-kappab by toll-like receptor 3 . Nature 2001;413:732-738. doi: 10.1038/35099560.

[7] Heil F, Hemmi H, Hochrein H, Ampenberger F, Kirschning C, Akira S, et al. Species-specific recognition of single-stranded RNA via toll-like receptor 7 and 8. Science 2004;303:1526-1529. doi: 10.1126/science.1093620.

[8] Oka T, Hikoso S, Yamaguchi O, Taneike M, Takeda T, Tamai T, et al. Mitochondrial DNA that escapes from autophagy causes inflammation and heart failure. Nature 2012;485:251-255. doi: 10.1038/nature10992.

[9] Desmet C], Ishii KJ. Nucleic acid sensing at the interface between innate and adaptive immunity in vaccination. Nat Rev Immunol 2012;12:479-491. doi: $10.1038 /$ nri3247.

[10] Kawai T, Akira S. The role of pattern-recognition receptors in innate immunity: Update on Toll-like receptors. Nat Immunol 2010;11:373-384. doi: 10.1038/ ni.1863.

[11] Haque A, Engwerda C. Hepatocytes break the silence during liver-stage malaria. Nat Med 2014;20:17-19. doi: 10.1038/nm.3446.

[12] Wu J, Chen ZJ. Innate immune sensing and signaling of cytosolic nucleic acids. Annu Rev Immunol 2014;32:461-488. doi: 10.1146/annurevimmunol-032713-120156.

[13] Leong CR, Oshiumi H, Suzuki T, Matsumoto M, Seya T. Nucleic acid sensors involved in the recognition of HBV in the liver-specific in vivo transfection mouse models-pattern recognition receptors and sensors for HBV. Med Sci 2015;3:16-24. doi: 10.3390/medsci3020016.

[14] Chiu YH, MacMillan JB, Chen ZJ. RNA polymerase III detects cytosolic DNA and induces type I interferons through the RIG-I pathway. Cell 2009;138: 576-591. doi: 10.1016/j.cell.2009.06.015.

[15] Satoh T, Kato H, Kumagai Y, Yoneyama M, Sato S, Matsushita K, et al. LGP2 is a positive regulator of RIG-I- and MDA5-mediated antiviral responses. Proc Natl Acad Sci U S A 2010;107:1512-1517. doi: 10.1073/pnas.0912986107.

[16] Schulz O, Pichlmair A, Rehwinkel J, Rogers NC, Scheuner D, Kato H, et al. Protein kinase $\mathrm{R}$ contributes to immunity against specific viruses by regulating interferon mRNA integrity. Cell Host Microbe 2010;7:354-361. doi: 10.1016/ j.chom.2010.04.007.

[17] Yang YL, Reis LF, Pavlovic J, Aguzzi A, Schafer R, Kumar A, et al. Deficient signaling in mice devoid of double-stranded RNA-dependent protein kinase. EMBO J 1995;14:6095-6106.

[18] Jiang Z, Zamanian-Daryoush M, Nie H, Silva AM, Williams BR, Li X. Poly(I-C)induced Toll-like receptor 3 (TLR3)-mediated activation of NF- $\mathrm{B} B$ and MAP kinase is through an interleukin-1 receptor-associated kinase (IRAK)independent pathway employing the signaling components TLR3-TRAF6TAK1-TAB2-PKR. J Biol Chem 2003;278:16713-16719. doi: 10.1074/jbc. M300562200.

[19] Lu B, Nakamura T, Inouye K, Li J, Tang Y, Lundback P, et al. Novel role of PKR in inflammasome activation and HMGB1 release. Nature 2012;488:670674. doi: 10.1038/nature11290.

[20] Sabbah A, Chang TH, Harnack R, Frohlich V, Tominaga K, Dube PH, et al. Activation of innate immune antiviral responses by Nod2. Nat Immunol 2009;10:1073-1080. doi: 10.1038/ni.1782.

[21] Sun L, Wu J, Du F, Chen X, Chen ZJ. Cyclic GMP-AMP synthase is a cytosolic DNA sensor that activates the type i interferon pathway. Science 2013;339: 786-791. doi: 10.1126/science.1232458.

[22] Schroder K, Tschopp J. The inflammasomes. Cell 2010;140:821-832. doi: 10.1016/j.cell.2010.01.040.

[23] Shao W, Yeretssian G, Doiron K, Hussain SN, Saleh M. The caspase-1 digestome identifies the glycolysis pathway as a target during infection and septic shock. J Biol Chem 2007;282:36321-36329. doi: 10.1074/jbc.M708182200.

[24] Sun Q, Gao W, Loughran P, Shapiro R, Fan J, Billiar TR, et al. Caspase 1 activation is protective against hepatocyte cell death by up-regulating beclin 1 protein and mitochondrial autophagy in the setting of redox stress. J Biol Chem 2013;288:15947-15958. doi: 10.1074/jbc.M112.426791.

[25] Rathinam VA, Jiang Z, Waggoner SN, Sharma S, Cole LE, Waggoner L, et al. The AIM2 inflammasome is essential for host defense against cytosolic bacteria and DNA viruses. Nat Immunol 2010;11:395-402. doi: 10.1038/ni. 1864.

[26] Dombrowski Y, Peric M, Koglin S, Kaymakanov N, Schmezer V, Reinholz M, et al. Honey bee (Apis mellifera) venom induces AIM2 inflammasome activation in human keratinocytes. Allergy 2012;67:1400-1407. doi: 10.1111/ all.12022.

[27] Shimada K, Crother TR, Karlin J, Dagvadorj J, Chiba N, Chen S, et al. Oxidized mitochondrial DNA activates the NLRP3 inflammasome during apoptosis. Immunity 2012;36:401-414. doi: 10.1016/j.immuni.2012.01.009.

[28] Dienstag JL. Hepatitis B virus infection. N Engl J Med 2008;359:1486-1500. doi: $10.1056 /$ NEJMra0801644. 
[29] Leong CR, Oshiumi $H$, Okamoto $M$, Azuma M, Takaki H, Matsumoto M, et al. A MAVS/TICAM-1-independent interferon-inducing pathway contributes to regulation of hepatitis $B$ virus replication in the mouse hydrodynamic injection model. J Innate Immun 2015;7:47-58. doi: 10.1159/000365113.

[30] Sato S, Li K, Kameyama T, Hayashi T, Ishida Y, Murakami S, et al. The RNA sensor RIG-I dually functions as an innate sensor and direct antiviral factor for hepatitis B virus. Immunity $2015 ; 42: 123-132$. doi: $10.1016 / j$.immuni. 2014.12.016.

[31] Halegoua-De Marzio D, Hann HW. Then and now: The progress in hepatitis $B$ treatment over the past 20 years. World J Gastroenterol 2014;20:401-413. doi: $10.3748 /$ wjg.v20.i2.401.

[32] Lu HL, Liao F. Melanoma differentiation-associated gene 5 senses hepatitis B virus and activates innate immune signaling to suppress virus replication. J Immunol 2013;191:3264-3276. doi: 10.4049/jimmunol.1300512.

[33] Eroglu C, Leblebicioglu H, Gunaydin M, Turan D, Sunbul M, Esen S, et al. Distinguishing hepatitis $B$ virus (HBV) genotype $D$ from non-D by a simple PCR. J Virol Methods 2004;119:183-187. doi: 10.1016/j.jviromet.2004.03. 003.

[34] Zhen J, Zhang L, Pan J, Ma S, Yu X, Li X, et al. AIM2 mediates inflammationassociated renal damage in hepatitis $B$ virus-associated glomerulonephritis by regulating caspase- $1, \mathrm{IL}-1 \beta$, and IL-18. Mediators Inflamm 2014;2014: 190860. doi: 10.1155/2014/190860.

[35] Cao X, Ding Q, Lu J, Tao W, Huang B, Zhao Y, et al. MDA5 plays a critical role in interferon response during hepatitis $C$ virus infection. J Hepatol 2015;62: 771-778. doi: 10.1016/j.jhep.2014.11.007.

[36] McHutchison JG. Understanding hepatitis C. Am J Manag Care 2004;10: S21-29.

[37] Stumper R Jr, Loo YM, Foy E, Li K, Yoneyama M, Fujita T, et al. Regulating intracellular antiviral defense and permissiveness to hepatitis $C$ virus RNA replication through a cellular RNA helicase, RIG-I. J Virol 2005;79:26892699. doi: 10.1128/JVI.79.5.2689-2699.2005.

[38] Fried MW, Shiffman ML, Reddy KR, Smith C, Marinos G, Goncales FL Jr, et al. Peginterferon alfa-2a plus ribavirin for chronic hepatitis $C$ virus infection. N Engl J Med 2002;347:975-982. doi: 10.1056/NEJMoa020047.

[39] Saito T, Owen DM, Jiang FG, Marcotrigiano J, Gale M. Innate immunity induced by composition-dependent rig-i recognition of hepatitis c virus rna. Nature 2008;454:523-527. doi: 10.1038/nature07106.

[40] Lee HC, Narayanan S, Park SJ, Seong SY, Hahn YS. Transcriptional regulation of IFN- $\lambda$ genes in hepatitis $C$ virus-infected hepatocytes via IRF-3.IRF-7.NF-кB complex. J Biol Chem 2014;289:5310-5319. doi: 10.1074/jbc.M113.536102.

[41] Li K, Chen Z, Kato N, Gale M Jr, Lemon SM. Distinct poly(I-C) and virus-activated signaling pathways leading to interferon-beta production in hepatocytes. J Biol Chem 2005;280:16739-16747. doi: 10.1074/jbc.M414139200.

[42] Saito T, Hirai R, Loo YM, Owen D, Johnson CL, Sinha SC, et al. Regulation of innate antiviral defenses through a shared repressor domain in RIG-I and LGP2. Proc Natl Acad Sci U S A 2007;104:582-587. doi: 10.1073/pnas. 0606699104.

[43] Pflugheber J, Fredericksen B, Sumpter R Jr, Wang C, Ware F, Sodora DL, et al. Regulation of PKR and IRF-1 during hepatitis $C$ virus RNA replication. Proc Natl Acad Sci U S A 2002;99:4650-4655. doi: 10.1073/pnas.062055699.

[44] Burdette D, Haskett A, Presser L, McRae S, Iqbal J, Waris G. Hepatitis C virus activates interleukin-1 $\beta$ via caspase-1-inflammasome complex. J Gen Virol 2012;93:235-246. doi: 10.1099/vir.0.034033-0.

[45] Chen W, Xu Y, Li H, Tao W, Xiang Y, Huang B, et al. HCV genomic RNA activates the NLRP3 inflammasome in human myeloid cells. PLoS One 2014;9: e84953. doi: 10.1371/journal.pone.0084953.

[46] Li K, Li NL, Wei D, Pfeffer SR, Fan M, Pfeffer LM. Activation of chemokine and inflammatory cytokine response in hepatitis $C$ virus-infected hepatocytes depends on Toll-like receptor 3 sensing of hepatitis $C$ virus double-stranded RNA intermediates. Hepatology 2012;55:666-675. doi: 10.1002/hep. 24763.

[47] Adams DH, Hubscher SG. Systemic viral infections and collateral damage in the liver. Am J Pathol 2006;168:1057-1059. doi: 10.2353/ajpath.2006.051296.

[48] Ison MG. Adenovirus infections in transplant recipients. Clin Infect Dis 2006; 43:331-339. doi: 10.1086/505498.

[49] Bowman JS, Green M, Scantlebury VP, Todo S, Tzakis A, Iwatsuki S, et al. OKT3 and viral disease in pediatric liver transplant recipients. Clin Transplant $1991 ; 5: 294-300$.
[50] Lam E, Stein S, Falck-Pedersen E. Adenovirus detection by the cGAS/STING/ TBK1 DNA sensing cascade. J Virol 2014;88:974-981. doi: 10.1128/ JVI.02702-13.

[51] Stein SC, Falck-Pedersen E. Sensing adenovirus infection: Activation of interferon regulatory factor 3 in RAW 264.7 cells. J Virol 2012;86:4527-4537. doi: $10.1128 /$ JVI.07071-11.

[52] Tabeta K, Georgel P, Janssen E, Du X, Hoebe K, Crozat K, et al. Toll-like receptors 9 and 3 as essential components of innate immune defense against mouse cytomegalovirus infection. Proc Natl Acad Sci U S A 2004; 101:3516-3521. doi: 10.1073/pnas.0400525101.

[53] DeFilippis VR, Alvarado D, Sali T, Rothenburg S, Früh K. Human cytomegalovirus induces the interferon response via the DNA sensor ZBP1. J Virol 2010;84:585-598. doi: 10.1128/JVI.01748-09.

[54] Li T, Chen J, Cristea IM. Human cytomegalovirus tegument protein pUL83 inhibits IFI16-mediated DNA sensing for immune evasion. Cell Host Microbe 2013;14:591-599. doi: 10.1016/j.chom.2013.10.007.

[55] Zhang $Q$, Raoof $M$, Chen $Y$, Sumi $Y$, Sursal $T$, Junger $W$, et al. Circulating mitochondrial DAMPs cause inflammatory responses to injury. Nature 2010;464:104-107. doi: 10.1038/nature08780.

[56] Imaeda AB, Watanabe A, Sohail MA, Mahmood S, Mohamadnejad M, Sutterwala FS, et al. Acetaminophen-induced hepatotoxicity in mice is dependent on TIr9 and the Nalp3 inflammasome. J Clin Invest 2009;119: 305-314. doi: 10.1172/jci35958.

[57] Marques PE, Oliveira AG, Pereira RV, David BA, Gomides LF, Saraiva AM, et al. Hepatic DNA deposition drives drug-induced liver injury and inflammation in mice. Hepatology 2015;61:348-360. doi: 10.1002/hep.27216.

[58] Bamboat ZM, Balachandran VP, Ocuin LM, Obaid H, Plitas G, DeMatteo RP. Tolllike receptor 9 inhibition confers protection from liver ischemia-reperfusion injury. Hepatology 2010;51:621-632. doi: 10.1002/hep.23365.

[59] Huang H, Evankovich J, Yan W, Nace G, Zhang L, Ross M, et al. Endogenous histones function as alarmins in sterile inflammatory liver injury through Tolllike receptor 9 in mice. Hepatology 2011;54:999-1008. doi: 10.1002/hep. 24501.

[60] Wang G, Wang H, Singh S, Zhou P, Yang S, Wang Y, et al. ADAR1 prevents liver injury from inflammation and suppresses interferon production in hepatocytes. Am J Pathol 2015;185:3224-3237. doi: 10.1016/j.ajpath.2015. 08.002.

[61] Yang S, Deng P, Zhu Z, Zhu J, Wang G, Zhang L, et al. Adenosine deaminase acting on RNA 1 limits RIG-I RNA detection and suppresses IFN production responding to viral and endogenous RNAs. J Immunol 2014;193:34363445. doi: 10.4049/jimmunol.1401136.

[62] Wang H, Wang G, Zhang L, Zhang J, Zhang J, Wang Q, et al. ADAR1 suppresses the activation of cytosolic RNA-sensing signaling pathways to protect the liver from ischemia/reperfusion injury. Sci Rep 2016;6:20248. doi: 10. 1038/srep20248.

[63] Pestal K, Funk CC, Snyder JM, Price ND, Treuting PM, Stetson DB. Isoforms of RNA-editing enzyme ADAR1 independently control nucleic acid sensor MDA5-driven autoimmunity and multi-organ development. Immunity 2015;43:933-944. doi: 10.1016/j.immuni.2015.11.001.

[64] Zhai Y, Qiao B, Gao F, Shen X, Vardanian A, Busuttil RW, et al. Type I, but not type II, interferon is critical in liver injury induced after ischemia and reperfusion. Hepatology 2008;47:199-206. doi: 10.1002/hep.21970.

[65] Scott MJ, Chen C, Sun Q, Billiar TR. Hepatocytes express functional NOD1 and NOD2 receptors: A role for NOD1 in hepatocyte CC and CXC chemokine production. J Hepatol 2010;53:693-701. doi: 10.1016/j.jhep.2010.04.026.

[66] LiehI P, Zuzarte-Luis V, Chan J, Zillinger T, Baptista F, Carapau D, et al. Hostcell sensors for plasmodium activate innate immunity against liver-stage infection. Nat Med 2014;20:47-53. doi: 10.1038/nm.3424.

[67] Julian MW, Shao G, Bao S, Knoell DL, Papenfuss TL, VanGundy ZC, et al. Mitochondrial transcription factor a serves as a danger signal by augmenting plasmacytoid dendritic cell responses to DNA. J Immunol 2012;189:433443. doi: 10.4049/jimmunol.1101375.

[68] Huang H, Chen HW, Evankovich J, Yan W, Rosborough BR, Nace GW, et al. Histones activate the NLRP3 inflammasome in kupffer cells during sterile inflammatory liver injury. J Immunol 2013;191:2665-2679. doi: 10 . 4049/jimmunol.1202733. 